\title{
CRISIS REGULATORIA, PLURALISMO JURÍDICO Y NUEVOS PARADIGMAS DEL DERECHO
}

\section{REGULATORY CRISIS, LEGAL PLURALISM AND NEW PARADIGMS OF LAW}

\author{
ALFONSO DE JULIOS-CAMPUZANO \\ Catedrático de Filosofía del Derecho da Universidad de Sevilla. Sevilla, España. \\ julios@us.es
}

\begin{abstract}
RESUMEN
El artículo está compartido en cuatro partes. La primera trata de la "Globalización y nuevas instancias de regulación", donde el fenómeno de la globalización constituye una de las claves explicativas de nuestro tiempo, con una gran capacidad transformadora transmutando drásticamente los procesos socioeconómicos. En la segunda, es subrayado sobre "El fin del monopolio estatal de la producción jurídica", donde resta evidente que la globalización ha generado nuevas interacciones que colisionan con los esquemas clásicos de validez y vigencia territorial de las normas jurídicas $y$, en la medida en que esto sucede, el derecho se queda inerme ante su incapacidad para dar una respuesta adecuada a fenómenos que escapan a la posibilidad de un control inmediato y directo por parte del derecho estatal. Ya, en la tercera parte, donde se escribe sobre "El pluralismo jurídico y la quiebra del derecho moderno", enuncia un proceso de multiplicación y descentralización de las instancias de producción normativa en paralelo a la aparición de nuevos actores en la escena internacional. Por fin, el texto busca responder la pregunta: Existe ¿Un nuevo paradigma jurídico?" quedando claro, que la globalización exige una recomposición de lo jurídico.
\end{abstract}

Palabras-clave: Globalización; Producción jurídica; Quiebra del derecho moderno.

\begin{abstract}
The article is shared in four parts. First talks about "globalization and new instances of regulation", where the phenomenon of globalization is one of the explanatory keys of our time, with a large processing capacity transmuting drastically socio-economic processes. In the second, is underlined on "The end of the State of the legal production monopoly", that it remains clear that globalization has generated new interactions that collide with classic validity and territorial legal rules effective schemes and, to the extent that this happens, the right remains unarmed to his failure to give an adequate response to phenomenon that are beyond the possibility of immediate and direct State control. Already, in the third part, about "legal pluralism and the bankruptcy of modern law", it outlines a process of multiplication and decentralization of instances of normative production in parallel with the emergence of new actors on the international scene. Finally, the text seeks to answer the question: "is there a new legal paradigm?" being of course, that globalization demands a recomposition of the legal.
\end{abstract}

Keywords: Globalization; Legal production; Bankruptcy of modern law 


\section{(1)

\section{SUMÁRIO}

1 GLOBALIZACIÓN E NUEVAS INSTANCIAS DE REGULACIÓN; 2 EL FIN DEL MONOPOLIO ESTATAL DE LA PRODUCCIÓN JURIDICA; 3 EL PLURALISMO JURIDICO Y LA QUIEBRA DEL DERECHO MODERNO; 4 ¿UN NUENO PARADIGMA JURIDICO? CONCLUSION; REFERENCIAS.

\section{GLOBALIZACIÓN Y NUEVAS INSTANCIAS DE REGULACIÓN}

El fenómeno de la globalización constituye, sin duda alguna, una de las claves explicativas de nuestro tiempo. Su capacidad transformadora está transmutando drásticamente los procesos socioeconómicos y forzando, simultáneamente, un amplio repertorio de cambios complejos que alcanzan a los diferentes ámbitos de la vida social, desde la política a la cultura, desde las relaciones humanas hasta el derecho. Por globalización nos referimos, pues, a un conjunto poliédrico y a menudo contradictorio de procesos económicos, políticos, sociales y culturales que son característicos de nuestra era. En términos económicos, las figuras más relevantes de la globalización, liderada por firmas multinacionales, son el desarrollo de redes de producción internacionales, la dispersión de las plantas de producción entre diferentes países, la fragmentación técnica y funcional de la producción, la fragmentación de la propiedad, la flexibilidad de los procesos productivos, el abastecimiento mundial, la interpenetración de los mercados financieros internacionales, los flujos transnacionales de información, los cambios en la naturaleza del empleo y el surgimiento de nuevas formas de trabajo. Desde este punto de vista la globalización ha traído consigo un policentrismo decisorio que se concreta en la aparición de nuevos actores, tales como las organizaciones no gubernamentales, las corporaciones transnacionales y los nuevos movimientos sociales, y ha tendido a debilitar, fragmentar e incluso reestructurar el Estado ${ }^{1}$.

Quizás, por ello, esa confluencia masiva de mutaciones trascendentales a nivel global que esta transmutando el mundo y la imagen que de él percibimos y aprehendemos, ha hecho notar a algún pensador que tal avalancha unida a la compleja red de conexiones políticas, sociales, económicas, culturales, que se suceden a ritmo frenético resulte difícil de comprender aplicando los criterios organizativos de otras épocas².

\footnotetext{
${ }^{1}$ SNYDER, F. Global Economics Networks and Global Legal Pluralism, EUI Working Papers, 99/6 European University Institute, Florencia, 1999, p. 6; Cfr. también, FARIA, J.E. Direito e Conjuntura, Saraiva, Sao Paulo, 2008, pp. 31 ss.

${ }^{2}$ Cfr. DOMINGO OSLÉ, R. ¿Qué es el Derecho global?, Consejo General del Poder Judicial, Madrid, 2008, p. 15.
} 
Cuál haya de ser el papel del derecho en todo este intrincado laberinto de reacciones encadenadas es algo que está aún por discernir, pero no sería lícito soslayar que la ruptura de paradigmas culturales homogéneos, la fragmentación sociopolítica y la consagración de la pluralidad y de la diferencia también en el ámbito de los órdenes jurídicos pueden comportar mutaciones de singular trascendencia que afecten de lleno a al propio orden jurídico y a la teoría del derecho en su configuración tradicional .

Partiendo de esta intuición, José Eduardo Faría advierte que la globalización precisa de la articulación de nuevos paradigmas de lo jurídico. Se trata, como puede apreciarse, de algo esencial a la tarea de reconstruir el fragmentado panorama de un derecho desbordado por la propia aceleración de las coordenadas espacio-tiempo. $Y$ es que el proceso exponencial de aceleración e integración de mercados, de flujos financieros, económicos y de mercancías a nivel planetario, ha provocado una espiral creciente de reacciones de descentralización y fragmentación del poder. La creciente concentración a nivel global del poder económico desafía continuamente las estructuras político-jurídicas contemporáneas que se ven desbordadas por la irrupción de las coordenadas tecnológicas en el ámbito de la producción, del consumo y de la distribución de los bienes. La generalización del uso de las nuevas tecnologías en los diversos sectores económicos, desde la producción de mercancías a los mercados financieros y de capitales, ha supuesto la creación de una tupida red de intereses transnacionales que escapan a todo control político.

El pensamiento jurídico contemporáneo parece estar enfrentándose a un drama de singular relevancia, pues hasta hace muy poco tiempo el escenario social, político, económico y cultural se había identificado con los Estados-nación y con su capacidad para articular y ordenar políticas públicas en orden a la consecución de determinados fines colectivos. El Estado, a través de sus mecanismos de representación y legitimación, era el principal actor de la vida política, un actor libre, autónomo y soberano, dotado de condiciones jurídicas y políticas para la producción de normas y la implementación de políticas. Y el ámbito internacional, durante mucho tiempo, fue también un desdoblamiento de las propias políticas y actores estatales ${ }^{3}$. Ese escenario es, ya, desde ahora, una reminiscencia del pasado. El complejo mundo de las relaciones internacionales ha dejado de ser unitario y también cesó de ser internacional en el sentido más

\footnotetext{
${ }^{3}$ FARIA, J.E.O Direito na economia globalizada, reimpr., Malheiros, Sao Paulo, 2000, p. 14. Cfr. también, FARIA, J.E. Pluralismo jurídico y regulación (ocho tendencias en el derecho contemporáneo). In: DE JULIOS-CAMPUZANO, A. (ed.) Ciudadanía y Derecho en la era de la globalización, Dykinson, Madrid, 2007, pp. 115-129.
} 
puro del término. Hablamos ya de un espacio global que es, a la vez, múltiple e interdependiente. Frente a la simplicidad del contexto internacional, el espacio global es, a su vez, el precipitado de una multiplicidad de espacios y de escenas geográfico-temporales que se superponen y que interseccionan. $Y$ en ese nuevo panorama el Estado queda descolocado, fuera de juego, al albur de las marejadas de múltiples e imprevisibles fuerzas de diversa naturaleza. En ese nuevo orden socio-económico poliédrico y multicéntrico,

el derecho positivo afronta dificultades crecientes en la edición de normas vinculantes para los distintos campos de la vida socioeconómica; sus "reglas de cambio", sus "reglas de reconocimiento" y sus "reglas de adjudicación", que hasta entonces aseguraban la operatividad y la funcionalidad del sistema jurídico, se revelan ahora ineficaces; los derechos individuales, los derechos políticos y los derechos sociales, institucionalizados desde hace tiempo, son crecientemente "flexibilizados" o "descontitucionalizados"; (...) y las tradicionales normas abstractas, generales e impersonales, articuladas en términos jerárquicos por una estructura constitucional, se ven crecientemente desafiadas en su efectividad por la aparición de reglas espontáneamente generadas en los diferentes ramos y sectores de la economía, a partir de sus necesidades específicas (como es el caso, por ejemplo, de los procedimientos normativos provenientes de las prácticas mercantiles adoptadas por las empresas transnacionales en la economía mundial) ${ }^{4}$.

\section{EL FIN DEL MONOPOLIO ESTATAL DE LA PRODUCCIÓN JURÍDICA}

Es evidente que la globalización ha generado nuevas interacciones que colisionan con los esquemas clásicos de validez y vigencia territorial de las normas jurídicas y, en la medida en que esto sucede, el derecho se queda inerme ante su incapacidad para dar una respuesta adecuada a fenómenos que escapan a la posibilidad de un control inmediato y directo por parte del derecho estatal. Inmerso en esa preocupación, Jarrod Wiener se pregunta por el impacto de la globalización en términos de producción normativa y de armonización jurídica. La disolución de las coordenadas espacio/tiempo, merced a la contribución de las nuevas tecnologías, ha traído consigo algunos problemas de indudable calado que conciernen, por ejemplo, a conflictos en torno a cuál haya de ser la legislación aplicable en múltiples supuestos, cuestión particularmente candente a la vista de las inagotables posibilidades que ofrece Internet para la criminalidad internacional: ¿cómo ha de procederse -por ejemplo- cuando un delito se produce a

\footnotetext{
${ }^{4}$ FARIA, J.E.; O Direito na economia globalizada, cit., p.15.
} 
través de la red desde un tercer Estado no afectado directamente por la acción delictiva? Estos y otros interrogantes conducen al autor a concluir que

la tecnología ha conectado a sociedades e individuos situados en diferentes partes del globo hasta tal extremo que el potencial surgido de esa miríada de relaciones sociales ha avanzado mucho mas rápido que las instituciones sociales que gobiernan esas relaciones. Los individuos se han convertido en actores globales, mientras que las estructuras que establecen reglas, derechos y obligaciones permanecen unidas al territorio y a una concepción de la sociedad previa a la era de la información.

La porosidad del Estado es también la porosidad del derecho estatal y de la concepción sistemática que le es inherente. El ordenamiento jurídico es ya otra cosa. La estructura piramidal que tanto juego había dado hasta ahora para explicar y comprender la jerarquía normativa y el principio de unidad es ya una pieza de museo entre los recursos pedagógicos de la docencia del derecho. El perfil arquitectónico del derecho contemporáneo no puede ser reconducido a la estructura convencional de un sistema ordenado en función de su jerarquía siguiendo un esquema piramidal. La complejidad creciente de nuestras sociedades y de su producción jurídica no se compadece bien con esa representación simplista del ordenamiento, cuyo valor simbólico queda desbordado por la propia dinámica de las relaciones sociales vertiginosas, desterritorializadas y transversales. La pluralidad de situaciones sociales, económicas, políticas y culturales no resulta compatible con una concepción normativa que se sustenta en base a los principios de impersonalidad, generalidad, abstracción y rigor semántico y organizado bajo la forma de un sistema cerrado, coherente, exento de lagunas y antinomias .

El concepto de orden en su dimensión tradicional parece así desvanecerse; en su lugar, parece que sólo podemos aspirar a un equilibrio precario que permita salvaguardar una dosis relativa de seguridad jurídica. La superposición de los múltiples niveles de juridicidad y su frecuente solapamiento introduce de esta forma un elemento desestabilizador en aquella concepción sólidamente asentada del derecho cierto, previsible y regular. La multiplicación de las instancias legislativas y la propia proliferación de arsenal normativo estatal han creado un panorama difuso en el que el concepto de ordenamiento en su acepción clásica o tradicional ha quedado diluido: mortal para el legalismo estatalista, sino que obliga también a replantearse en 
otros términos la idea de unidad del ordenamiento; unidad que ya no puede lograrse a través de un sistema jurídico jerarquizado y escalonado, sino que precisamente intenta reconstruirse a partir de la Constitución como expresión de un marco de consenso y unidad, ya no formal, sino material y sustantivo y, sobre todo, procedimental, donde han de coexistir diversas concepciones de la justicia.

La multiplicación de las instancias productoras de derecho y la concatenación de sus respectivos ámbitos de validez convierte al sistema jurídico en algo abierto, flexible y poroso cuyas normas se entrelazan sin fin con normas procedentes de distintas instancias, de modo que el sistema se expande a través de los múltiples nexos colaterales de complejas redes normativas. En este nuevo escenario el reparto ha cambiado: ya no es el Estado el que asume el peso de la función; amén de un amplio repertorio de instancias creadoras de juridicidad, al margen de la propia oficialidad estatal, el Estado ha de convivir con agencias administrativas, corporaciones de derecho público, que participan de redes normativas de carácter transnacional. Como ha puesto de relieve Slaughter, estas nuevas agencias estatales poseen autonomía y capacidad reguladora y se relacionan entre ellas a través de complejas redes que se extienden por todo el mundo. Estas “redes gubernamentales” o, más generalmente, “redes regulatorias transgubernamentales" actúan de forma rápida, flexible y descentralizada, atributos que le permiten funcionar de forma óptima en un medio ambiente de informaciones vertiginosamente cambiante .

Esta proliferación pone de relieve que la interdependencia y homogeneización de lo económico no va seguida de un proceso paralelo en el ámbito jurídico, cuyos centros de producción se multiplican a nivel global abriendo con ello una fase de feudalización de lo jurídico: frente a la razonable unidad en los focos de producción legislativa del Estado-nación, la globalización ha comportado un proceso de fragmentación, de descentralización y de multiplicación de las esferas de producción jurídica .

A medida que se intensifican los intercambios y se avanza en el desarrollo de la interdependencia, la globalización hace emerger nuevas fuentes de normatividad, nuevos actores jurídicos, cuya producción normativa, diversa, plural y flexible, colisiona con los esquemas clásicos de la positividad estatal. De este modo, las instituciones legislativas tradicionales ceden lugar a fuentes supranacionales -a través de la transferencia de competencias legales desde el Estado-nación a organismos multilaterales-, a fuentes privadas integradas por prácticas y cauces regulatorios desarrollados en el ámbito del comercio transnacional, empresas y asociaciones profesionales y del tejido asociativo iusprivatista que le acompaña-, a fuentes técnicas -basadas en el poder creciente de los expertos en las sociedades 
complejas de nuestro tiempo- y a fuentes comunitarias -que expresan la capacidad de articulación de la sociedad civil, incluso en el ámbito transnacional, a través del poder creciente de movilización que representan las ONG's y los movimientos sociales -. El carácter distintivo de ese derecho global -indica Fitzpatrick- es que no es un derecho nacional; va más allá de él y, como consecuencia de ello, lo debilita y lo hace crecientemente irrelevante .

Ese pluralismo jurídico global, agrega Snyder, no es sólo una parte importante del contexto en el que las redes económicas globales se construyen, en el sentido de que es un factor que debe ser tenido en cuenta por los actores estratégicos, sino que es parte integrante, constitutiva, de las redes económicas globales: "En otras palabras, las redes económicas globales son construidas sobre un campo de juego global, que es organizado o estructurado parcialmente por el pluralismo jurídico global. El pluralismo jurídico global, sin embargo, no se limita a proporcionar las reglas del juego, sino que constituye el juego mismo, incluyendo a los jugadores.

No se puede soslayar que la ingente producción normativa de los múltiples centros de poder en la era de la globalización conculca garantías y principios esenciales del derecho moderno, como la propia publicidad de las normas y los cauces procesales de producción establecidos en garantía de los propios ciudadanos.

El impacto que la globalización tiene sobre la propia estructura estatal afecta, como es evidente, a su organización institucional y provoca una crisis del principio de soberanía que, de una u otra forma, se traduce a nivel interno también en forma de crisis de legitimidad. El surgimiento de cauces informales de producción jurídica alcanza a los mecanismos legitimadores del Estado de Derecho, de tal guisa que esas nuevas fuentes de producción normativa provocan la quiebra del principio democrático en la medida en que representan expresiones de juridicidad ajenas a los circuitos de formación de la voluntad colectiva.

De esta forma, la concepción monista del fenómeno jurídico, que identificaba el derecho con el derecho del Estado en cuanto derecho único y racional, es progresivamente suplantada por nuevos cauces y formas de producción jurídica que comienzan paulatinamente a abrirse paso en un contexto interdependiente; y esas nuevas formas jurídicas transnacionales permean los ámbitos hasta ahora impenetrables y autosuficientes de los ordenamientos jurídicos estatales.

Sin embargo, esa visión pluralista del fenómeno jurídico como algo esencialmente diverso y complejo compite con aquella configuración tradicional de lo jurídico como expresión de la estructura estatal, no sólo a nivel internacional sino también a nivel interno. El impacto de 
estas nuevas formas de juridicidad está aún por calibrar, pero estamos en condiciones de augurar que su irrupción anticipa el final de una época que, marcada por el apogeo de la concepción cientificista del derecho y de la dogmática jurídica, estableció una identificación plena entre los principios de legitimidad, estatalidad y racionalidad a tenor de la cual el derecho es considerado legítimo no en función de algún factor metajurídico, sino por ser el único derecho, estatal y racional. Esa identificación formal entre derecho y Estado a partir de la equiparación incondicional entre legitimidad y legalidad fue gráficamente reflejada por Kelsen cuando afirmó que todo Estado, por el mero hecho de serlo, es Estado de Derecho .

La descentralización del poder, la multiplicación y proliferación de instancias de gobierno en los distintos ámbitos de la vida social y política se traduce en una multiplicación de nuevas formas de producción jurídica, de suerte que la variedad normativa corresponde así a diversos niveles de alcance. En cualquier caso, el nuevo orden internacional emergente apunta hacia un orden multilateral en el que el Estado habrá de redefinir su papel en las nuevas coordenadas de la interdependencia y compartir el escenario que hasta ahora ocupaba en solitario con nuevos actores internacionales que constituyen, ya hoy, una pujante realidad; ese es el caso de las Organizaciones no Gubernamentales y de las corporaciones transnacionales. La transición desde una sociedad internacional hacia una sociedad global esta cristalizando en una organización multilateral del espacio transnacional, fiel reflejo de una sociedad civil crecientemente activa caracterizada por la proliferación, no necesariamente negativa, de actores transnacionales .

\section{EL PLURALISMO JURÍDICO Y LA QUIEBRA DEL DERECHO MODERNO}

Nuestra era, como ha advertido Volkmar Gessner, está marcada por la quiebra de la certeza jurídica que había constituido, durante siglos, la piedra angular de la racionalidad del derecho moderno. El impacto de la lex mercatoria sobre los órdenes normativos nacionales resulta extraordinariamente desestabilizador. Este orden normativo, apunta Gessner, está lejos de ser comprensible y puede conducir en muchos casos, por tanto, a la inseguridad y a la incertidumbre acerca de la situación jurídica. Sumidos en interminables redes normativas, vivimos al albur de complejas e indescifrables instancias de poder, conscientes de que el caudal normativo es mayor del que nadie jamás pudiera llegar a conocer. 
Este proceso de multiplicación y descentralización de las instancias de producción normativa es paralelo a la aparición de nuevos actores en la escena internacional, un complejo entramado de organizaciones empresariales cuyo ámbito trasciende cualquier concreta ubicación geográfica de carácter regional o internacional. Es la corporación transnacional que viene a sustituir a la caduca empresa multinacional. Y es que, como afirma Grahame Thompson, la corporación transnacional representa el epítome del capital global; su base de operaciones, más que un país concreto o un grupo de ellos, es la arena global. Se surte y manufactura en una amplia variedad de localizaciones geográficas a lo largo del planeta y tiene una visión global de su mercado, sin quedar reducida a un solo centro de operaciones .

Un nuevo modelo empresarial para desarrollar estrategias también novedosas y cuyo control escapa de pleno a las posibilidades regulatorias de los derechos estatales. Sus normas de carácter interno y sus acuerdos a nivel transnacional con otras corporaciones son, con frecuencia, inaccesibles a jurisdicción alguna de aliento estatal-internacional. Esta urdimbre jurídica informal distorsiona gravemente los procesos de producción normativa formales de los Estados y de los foros internacionales en los que éstos están representados y configura un panorama plural de producción jurídica en el que, de una u otra forma, las normas y acuerdos de las corporaciones transnacionales condicionan el margen de gobernabilidad de los Estados. De esta forma, el cambio radical en la dinámica de actuación del sistema de producción y de organización de los mercados a nivel planetario se constituye en un factor determinante de la crisis de las instituciones jurídicas del Estado-nación que se ven progresivamente desbordadas por las estructuras, mecanismos y procedimientos jurídicos surgidos en el ámbito de la economía global.

Consecuentemente, el derecho de los Estados compite en distintos ámbitos de validez personal, material, espacial o temporal con toda una tupida red de normas, en muchos casos informales, surgidas al abrigo de la expansión exponencial del mercado y del sistema de producción global, nuevas formas de juridicidad entre las que destacan la legislación producida por los organismos multilaterales, los nuevos patrones de contractualidad jurídica, el surgimiento de un derecho privado transnacional entre organizaciones, el desarrollo de un derecho "intraorganizacional" o la emergencia de la lex mercatoria, entre otras .

Ese desplazamiento de los poderes de decisión jurídica -nos recuerda Faria- genera la necesidad de organismos, mecanismos y sistemas supranacionales de coordinación macroeconómica, de orientación comercial, de armonización de las diferentes legislaciones en vigor, de articulación de intereses financieros y de resolución de los conflictos que pueden 
comprometer el "medio ambiente" de las instituciones financieras y de los agentes productivos en fin, de una inédita, amplia y compleja estructura jurídica de naturaleza multilateral destinada a asegurar el funcionamiento, sin riesgos, traumas e inseguridades, de un orden económico globalizado -. Evidentemente, como ha notado el profesor Pérez Luño, estos procesos erosionan los cauces de legitimación democrática de las normas jurídicas de los ordenamientos estatales en beneficio de una legitimación técnica basada en las exigencias de funcionamiento inherentes a la propia estructura del sistema .Justamente en este contexto, la labor normativa de las grandes empresas transnacionales, unida al protagonismo regulatorio de las grandes instancias económicas globales, ataca de lleno a la propia legitimidad de un orden jurídico cada vez más caótico que invade las esferas competenciales de los Estados.

La globalización comporta, a la postre, un fenómeno de disolución de lo jurídico en una miríada de normas difícilmente compatibles que se concreta en una espiral de producción normativa frenética y desordenada. Y cuanto más complejo se hace el sistema jurídico, más difícil resulta que pueda articular respuestas coherentes en la regulación de la vida social, de suerte que la juridificación vertiginosa del Estado contemporáneo provoca finalmente la ruptura de la unidad orgánica del ordenamiento. Frente a la concepción tradicional de éste como un único cuerpo jurídico, coherentemente articulado y jerárquicamente ordenado en normas completas y precisas, el nuevo paradigma que comienza a emerger anuncia desde ahora el ocaso del paradigma "cientificista” del derecho y de la concepción monista de la producción jurídica.

La diversificación entraña ruptura y desmembramiento: el derecho como un conjunto heterogéneo y plural con múltiples derivaciones y ramificaciones; el ordenamiento no como totalidad sino como complejidad, como una urdimbre heterónoma e interdependiente de normas de diversa índole, procedencia y naturaleza, que se mezclan y condicionan recíprocamente, al tiempo que se superponen y se confunden sus ámbitos de validez. La extraordinariamente múltiple, polimórfica y compleja gama normativa, con su variado repertorio de normas generales y excepcionales de carácter especial o particular, convierte la totalidad en un laberinto de redes de normas interconectadas y contradictorias. Y con ello el sistema jurídico crece y se multiplica exponencialmente en un conjunto de redes y cadenas normativas cuya congruencia interna es sólo una apariencia.

Asistimos, con ello, a la quiebra de algunos principios esenciales del derecho moderno:

a) El principio de racionalidad, profundamente afectado por la superposición de modelos de racionalidad contrapuestos que conforman tendencias conflictivas en el seno de los propios órdenes jurídicos. $\mathrm{Y}$ es que, como atinadamente ha señalado Lars Eriksson, en el 
derecho contemporáneo se está produciendo una confrontación entre dos modelos de racionalidad: de un lado, la racionalidad formal, concretada por la concepción dogmática tradicional que da cuerpo jurídico al Estado de Derecho liberal-burgués y que se concreta en el principio de la autonomía privada; de otro, la racionalidad material, incorporada al Derecho por obra de las transformaciones que la aparición del Estado social ha producido en el orden jurídico y que incorpora criterios sustantivos de justicia a través del principio de intervención estatal . La superposición del subsistema económico, con el postulado de la racionalidad instrumental, sobre el espacio de racionalidad de los objetivos estatales genera un desquiciamiento del orden jurídico que se traduce en un déficit de racionalidad del ordenamiento.

b) Fruto de lo anterior, los principios de unidad y coherencia se resquebrajan, provocando una fragmentación a nivel interno de los ordenamientos jurídicos estatales que aparecen, ahora ya, como un aglomerado de normas encadenadas por su propia secuencia lógica de validez, pero cuya unidad y congruencia material se ve acosada por la continua interferencia de otras esferas normativas de ámbito transnacional -oficiales o no- que determinan la eficacia de las propias normas jurídicas nacionales. Quiere ello decir que el orden jurídico comienza a dejar de ser tal, en la medida en que su ámbito de validez es amenazado de forma creciente por complejos entramados normativos elaborados en las altas instancias de los intereses económicos supranacionales, intereses cuya traducción en normas condena al derecho del Estado a la subordinación de lo público-estatal a lo privado-transnacional. Esta intersección de normas inter-trans-nacionales, fundamentalmente de carácter privado, genera, sin lugar a dudas, un proceso de deshilvanación de las estructuras jurídicas y de confusión de normas de muy diverso origen y ámbito de validez.

c) La superposición del subsistema económico como ámbito independiente de lo político y superior a él y su expansión sobre otros subsistemas de la vida social se traduce, también, en una crisis del principio de legitimidad del ordenamiento jurídico. Desde el momento en que la inflación normativa de las múltiples instancias creadoras de derecho "informal", interfiere y limita los propios ámbitos competenciales de los Estados-nación, el derecho se deslegitima pues sus contenidos normativos carecen con frecuencia del respaldo ciudadano a través de cauces democráticos de legitimación.

De esta guisa, se generan, en expresión de Habermas, "agujeros de legitimidad", ocasionados, fundamentalmente, por los desplazamientos de competencias del Estado no sólo a nivel supranacional. En este ámbito, la proliferación de organizaciones internacionales de configuración y características diversas provoca una eclosión de normatividades en conflicto que 
se interrelacionan creando relaciones mutuas de interdependencia y de recíproca exclusión. Junto a las organizaciones gubernamentales internacionales y las conferencias internacionales permanentes, las organizaciones no gubernamentales, como Amnistía Internacional y Greenpeace, tienen cada vez un poder mayor en el contexto transnacional y acceden con facilidad a la red informal de instancias productoras de derecho. A medida que la producción jurídica se descentraliza y los órganos de producción legislativa se multiplican, la legitimidad se difumina hasta convertirse en una mera exigencia formal, una apariencia de legitimidad que no satisface las demandas de democratización real de la ciudadanía. La legitimidad del orden jurídico es, cada vez más, una ilusión, una imagen mistificada, una ficción, en suma, cuya preservación se convierte en la tabla de salvación del propio ordenamiento jurídico, de la ciudadanía, de la democracia y del Estado de Derecho.

Asistimos, en definitiva, como ha aseverado Jarrod Wiener a la crisis del modelo jurídico instaurado tras la paz de Westfalia que consagró el liderazgo jurídico-político del Estado-nación en la esfera internacional a partir de la entronización de la soberanía territorial y la reserva a los Estados de la capacidad jurídica en el orden internacional. En las coordenadas de la globalización este orden parece estar en franco retroceso, cuando no seriamente amenazado. La soberanía territorial es, cada vez más, un concepto en periodo de redefinición: una soberanía que trasluce precariedad e interdependencia, una soberanía que sólo puede cimentarse sobre la incontestable realidad de la porosidad estatal y la cooperación mutua. En ese sentido, el concepto de soberanía necesita ser readaptado a las nuevas circunstancias del orden global: una soberanía cuya supervivencia depende en buena medida de su capacidad para reconocerse precaria, deficiente y profundamente condicionada por el vasto repertorio de acontecimientos de un mundo interconectado. El desafío al que hemos de hacer frente se define, pues, en estos términos: ¿cómo conciliar el sistema jurídico de Westfalia construido sobre la diferenciación y la compartimentación de diferentes jurisdicciones legales con las nuevas demandas de una sociedad civil cuyos actores con frecuencia se desenvuelven a nivel transnacional mediante la explotación de las tecnologías de la comunicación?

Twining ha apuntado que la gran tarea que se abre ante nosotros es la elaboración de una nueva dogmática jurídica generalista o universalista, capaz de superar aquella compartimentación geográfica del saber jurídico que vino a imponer el modelo del Estadonación: un nuevo saber sobre el derecho construido desde una perspectiva global, porque sólo en términos de globalidad podrá ser entendido el mundo en el futuro; una teoría del derecho de carácter cosmopolita, abierta, por tanto, a una concepción plural del fenómeno jurídico, 
superadora de las visiones estatalistas y de la perspectiva etnocéntrica que redujo el estudio del derecho a las dos grandes tradiciones jurídicas gestadas en Occidente: la tradición del common law y la tradición del derecho continental. Esto implica, sin perjuicio de un análisis pormenorizado, un renacimiento de la jurisprudencia general y una reconsideración del derecho comparado desde una perspectiva global como elementos claves de una perspectiva jurídica cosmopolita .

La globalidad, pues, ha de contemplarse desde una perspectiva poliédrica:

$1^{\circ}$. Desde la profunda interconexión de los saberes jurídicos entre sí y de éstos con el resto de los saberes: el derecho de nuestro tiempo no puede seguir siendo concebido como un saber neutro, aséptico e independiente, aislado con respecto a las aportaciones provenientes de otras ciencias, sino que hoy, por el contrario, se precisa un derecho permeable, flexible, abierto y en continua revisión. Se acabó el tiempo de los saberes conclusos y definitivos, cuya pose mayestática imponía, más que un severo respeto, un temor reverencial. La interdisciplinariedad es una de las características distintivas de nuestro tiempo a la que el pensamiento jurídico no puede quedar sustraído.

$2^{\circ}$. En segundo lugar, desde la perspectiva de la conexión global de los problemas humanos: a medida que el fenómeno de la globalización avanza, vamos adquiriendo una consciencia cada vez más diáfana del futuro común de la humanidad. Como consecuencia de ello, las normas jurídicas se multiplican a la par que las instancias productoras de derecho proliferan. La globalización es también la era de la descentralización y de la dispersión normativa: los niveles locales, nacionales y transnacionales se confunden, los ámbitos de validez se interpenetran: el derecho se vislumbra ya como una trama difusa de redes normativas cuyo principio y cuyo fin nadie acierta a ver. En esta encrucijada, el derecho internacional resulta un instrumento de dudosa utilidad para lograr reducir la complejidad normativa, un instrumento cuya insuficiencia se hace cada vez más patente a medida que logra superar las limitaciones impuestas por los actores transnacionales y particularmente por los Estados. Precisamente por ello, Rafael Domingo postula la progresiva suplantación del derecho internacional por el derecho global, pues aquél se construye sobre el reconocimiento del principio de igualdad entre los Estados y la afirmación dogmática de la soberanía, un concepto que, por otra parte, resulta regresivo y contramoderno para algunos autores. Ese soporte teórico del derecho internacional omitió el protagonismo de los ciudadanos que quedaron desplazados de su ámbito de actuación. Por eso, frente a la exaltación de la soberanía propia del derecho internacional, el derecho global opone una defensa radical de la dignidad de la persona. Algo con lo que coincide 
Habermas, al postular que el derecho internacional de nuestros días debe evolucionar hacia un derecho de vocación cosmopolita, lo cual comporta un desplazamiento desde la soberanía de los Estados como elemento vertebrador a la consagración efectiva de la dignidad humana como principio rector de ese nuevo orden jurídico cosmopolita .

Difícil tarea, ciertamente, si seguimos aferrados a los esquemas caducos de una Ciencia del Derecho forjada a la sombra del Estado. Nuestros problemas son consecuencia de la insuficiencia de ese modelo teórico maltrecho que apenas sirve sino para mostrarse vencido y superado. En el alborear de un nuevo siglo, los juristas tendrán que hacer frente a grandes desafíos. Ese es el reto que la teoría del derecho tiene ante sí: la búsqueda de respuestas ante realidades de hoy, que ya no pueden ser comprendidas con los esquemas caducos de un saber desbordado por la dinámica de los acontecimientos sociales. Construir la teoría jurídica del mañana requerirá, sin duda, un trabajo arduo que sólo ahora comenzamos a entrever.

\section{4 ¿UN NUEVO PARADIGMA JURÍDICO?}

La globalización, inopinadamente, supone fractura, multiplicación, descentralización y diversificación de las instancias jurídicas de producción normativa. Y esto conlleva, en última instancia, una quiebra del propio ordenamiento jurídico y de algunos de sus principios fundamentales. De este modo, la globalización permea las estructuras estatales y determina la propia producción jurídica de los Estados nacionales, condicionando seriamente la discrecionalidad de los legisladores y socavando la congruencia relativa entre los espacios políticos, económicos y culturales. Como consecuencia de ello, no sólo la soberanía nacional, sino también la categoría de soberanía popular, tan crucial para la idea democrática, se vuelve problemática . Queda claro, con ello, que la globalización exige una recomposición de lo jurídico, profundamente alterado en su funcionamiento por la irrupción de esas nuevas formas de producción normativa; recomposición que pasa necesariamente por la necesidad de concebir el derecho desde una perspectiva global, superando los localismos anacrónicos de los viejos sistemas jurídicos estatales para articular respuestas globales a problemas de alcance planetario.

En definitiva, el impacto que la globalización produce sobre el orden jurídico es, sin duda, trascendente. Tanto que voces autorizadas del pensamiento jurídico contemporáneo han coincidido en señalar que la irrupción de la globalización en el ámbito de las relaciones 
económicas, sociales y políticas provoca profundas alteraciones y disfunciones en la concepción jurídica tradicional, cuya vigencia se ve de esta forma cuestionada cada vez con mayor insistencia. La globalización introduce una ruptura con el paradigma jurídico anterior, en la medida en que rebasa los conceptos, categorías e instituciones del derecho regulador. Bien es cierto que la crisis paradigmática no es un fenómeno radicalmente nuevo. Va unida a la debilidad del paradigma jurídico del Estado social que se hace especialmente patente a partir de los años setenta y que adquiere carta de naturaleza, como recuerda Habermas, al convertirse en tema expreso de la dogmática jurídica. Como se ha notado con anterioridad, la crisis de ese paradigma tiene mucho que ver sin duda con la compleja, escabrosa e impenetrable estructura del orden jurídico del Estado social, en el que no sólo conviven distintas y contradictorias orientaciones programáticas -condicionales o finalistas-, sino que la sobreabundancia de normas y la aparición de tipologías normativas también novedosas con respecto al periodo anterior, como son las normas procedimentales y de organización, no contribuye a la racionalización y simplificación del sistema, antes bien, sigue compeliendo al legislador a regular materias complejas y ámbitos funcionales que obedecen a su propia lógica interna. Existe, además, una circularidad interna entre la complejidad del ordenamiento y la potestad regulatoria de la administración. En palabras de Schuck: “El movimiento hacia la potestad normativa de la administración esta íntimamente conectado con el creciente recurso a la discrecionalidad administrativa como modalidad legal dominante, y ese ejercicio de discrecionalidad genera, a su vez, mayor complejidad".

En nuestro tiempo, empero, esa sensación de crisis paradigmática parece haberse agudizado, en las medida en que ya no es sólo el paradigma del Estado social el que muestra debilidad, sino que la crisis afecta a la propia soberanía nacional y al modelo estatal de producción jurídica que manifiesta actualmente síntomas inequívocos de agotamiento. Sus principios resultan ya insuficientes, y su estructura jerárquica y su configuración unidimensional quedan en entredicho. El derecho del Estado es ahora sólo una de las formas posibles de juridicidad. Y no la más importante si atendemos a las limitaciones que los nuevos actores jurídicos introducen con sus nuevas formas de juridicidad en el espacio de gobernabilidad de los legisladores estatales. Por eso, quienes sostienen la tesis del agotamiento del paradigma jurídico basado en la unidad de producción normativa del Estado nacional alegan que el pluralismo normativo introduce un sesgo diferenciador esencial en el desarrollo del fenómeno jurídico en la era de la globalización. 
Asistimos, en suma, a los últimos estertores de una concepción jurídica cuya agonía preludia la emergencia de un nuevo paradigma de producción normativa más flexible y abierto, más poroso y permeable. El agotamiento paradigmático encierra en sí mismo el germen del paradigma emergente. Este es el tenor de la aportación del profesor portugués Boaventura de Sousa que inaugura su obra A crítica da razao indolente. Coincidimos, en este sentido, con la afirmación de Sousa Santos: los paradigmas socioculturales nacen temporalmente limitados, condicionados históricamente. La finitud de un paradigma coincide con la emergencia de otro, en una sucesión histórica sin solución de continuidad.

Creo que el derecho contemporáneo se haya atravesado diagonalmente por tendencias contradictorias, por elementos antagónicos y categorías y conceptos incompatibles. Ese agotamiento de paradigmas va indisociablemente unido, en opinión de Faria , a la insuficiencia del saber dogmático tradicional en cuanto saber pretendidamente aséptico, avalorativo y autosuficiente que reduce la experiencia jurídica a la dimensión estricta de la norma. Y es que la modernidad ha generado tendencias internas contrapuestas, fruto de la superposición en el ámbito jurídico de diversos modelos de racionalidad que hoy resultan irreconciliables. Es la confrontación entre el paradigma emancipador de la modernidad, que nace con la Ilustración y que se expresa en la formulación de una concepción sustantiva de la justicia vinculada a los derechos humanos de signo universal, y ese otro modelo que, apoyado en la exaltación paroxística del legalismo, vino a empaquetar los ideales ilustrados en el envoltorio presuntamente científico de una dogmática jurídica al servicio de intereses de clase. Es ese conflicto irresuelto el que vuelve a plantearse ahora con nuevos perfiles y con interrogantes también novedosos; un conflicto entre una concepción cientificista del derecho que quiso convertirlo en un producto aséptico, inaccesible a las demandas sociales y ajeno a las concretas necesidades históricas: un derecho pagado de sí mismo, ensoberbecido y ebrio de la "racionalidad universal" con que el legislador burgués lo había revestido; un derecho forjado a la sombra del Estado, al servicio de intereses de clase que, concebido como sistema pleno, autárquico y coherente, miraba con desprecio a la interpretación: todo lo que necesitaba era la aplicación lógico-deductiva de los principios generales contenidos en las normas. A la sombra de esta concepción jurídica, la Ciencia del derecho proporcionó los mimbres teóricos: conceptos y categorías que no eran en absoluto asépticos, formulados con una finalidad claramente legitimadora del orden existente.

Hoy, decimos, ese conflicto vuelve a emerger, con otros ropajes, para plantearnos problemas que, a pesar de su novedad, son tan de hoy como de ayer: es el eterno problema de 
la justicia, de las relaciones entre moralidad y derecho y de la existencia de valores universales; cuestiones que la globalización ha vuelto a poner ante nuestro ojos, mostrándonos que existen, ciertamente, problemas globales que no pueden ser abordados desde la perspectiva parroquiana del derecho local; que nuestro mundo es un legado cuya riqueza biológica debe ser preservada en atención a las generaciones futuras y que los derechos humanos precisan de una implementación a nivel global. Ante las profundas transformaciones que se han operado en las últimas décadas, es necesario reconocer que la ciencia del Derecho ha devenido obsoleta, que sus elaboraciones conceptuales y sus modelos explicativos resultan ya insuficientes para explicar una compleja variedad de fenómenos y que todo empeño por aprehender la realidad jurídica desde sus coordenadas teóricas resulta, en última instancia, una empresa estéril.

La Ciencia del derecho, en suma, ha sido superada por los hechos y por las circunstancias de este mundo cambiante, de modo que, como ha señalado Domingo Oslé, la complejidad creciente de las dinámicas sociales ha revelado la insuficiencia, el agotamiento de muchos principios jurídicos cuya permanencia y estabilidad podría resultar incuestionada pero cuyo carácter contingente, los revela en la actualidad como elaboraciones de otra época . Una afirmación de ese tenor no puede sino conducir a la constatación de la crisis de paradigmas que la globalización ha provocado, crisis que alcanza de lleno al paradigma jurídico de la modernidad que, en las coordenadas actuales, precisa ser reformulado, crisis, en suma, que impone la necesidad de un cambio radical de la Ciencia jurídica, que demanda "una auténtica revolución que, sin abandonar el acervo de la tradición, redefina el sendero del Derecho de cara al tercer milenio" .

Vivimos, por tanto, una época de transición paradigmática en la que paulatinamente los perfiles del derecho van mudando en su configuración. Siguiendo a Kuhn en La estructura de las revoluciones científicas, toda mudanza de paradigma comporta una mutación profunda de la propia ciencia, que se ve compelida a revisar teorías, métodos y reglas, alterándose, consecuentemente, los criterios que determinan la legitimidad, tanto de los problemas como de las soluciones propuestas. Las hipótesis, elevadas a teorías de acuerdo con las reglas de un paradigma, pueden perder su crédito según las reglas del nuevo paradigma. La revolución científica entraña, por ende, una crisis que se sustancia en el cambio de paradigma ; es decir, que las condiciones de posibilidad del conocimiento científico dependen de paradigmas que pueden cambiar con el transcurso del tiempo.

En su obra Law in Modern Society. Towards a Criticism of Social Theory, Roberto Mangabeira Unger mostró ese condicionamiento sociocultural del fenómeno jurídico. La obra de 
Unger refleja un empeño sistematizador por mostrar la gestación de un determinado modelo teórico de derecho -el derecho moderno- que es, fundamentalmente, un producto histórico, la resultante de una serie de variables históricas cuya gestación está profundamente unida a los parámetros culturales de la sociedad en que se desarrolla. De suerte que, a la par que se desarrolla el derecho, se desarrolla también un edificio teórico que proporciona un modelo explicativo y un método de análisis, cuyas características distintivas resultan ser, también, productos culturales .

De ello se desprende que el carácter esencialmente cultural del pensamiento jurídico y de sus elaboraciones conceptuales no puede permanecer ajeno a la propia dinámica de la evolución histórica, de modo que todo saber jurídico está directamente condicionado por los modelos culturales imperantes y por el paradigma de producción científica con arreglo al cual el conocimiento puede ser considerado tal.

La crisis del derecho que comienza a preocupar a un sector cada vez más amplio de la doctrina guarda una íntima relación con las profundas transformaciones socioculturales de nuestro tiempo. Se trata de un conflicto entre dos realidades: una que emerge, que pugna por salir a la luz, y otra que se resiste a ser desplazada. $Y$ esa confrontación no puede ser en absoluto pacífica, porque atañe a nuestro modo de entender la relación del hombre con el mundo y a nuestro modo de aprehender intelectivamente la realidad. Lo que está en juego no es sólo nuestra forma de entender la realidad sino cuál ha de ser el papel del hombre ante una realidad que está cambiado sustancialmente. No se trata, simplemente, de cambiar nuestra forma de entender el mundo, sino de adaptar nuestra comprensión del mundo a las exigencias de fenómenos emergentes que están trastocando la realidad. Por eso, si el derecho es parte esencial de nuestra visión del mundo, forzosamente tiene que verse afectado por los cambios vertiginosos que se están operando. $Y$ ante ese cúmulo de nuevas situaciones, el ordenamiento jurídico en su formulación tradicional se desquicia, se agrieta y se resquebraja, porque en él confluyen al mismo tiempo esas dos caras agitadas y convulsas de la realidad: la que emerge y la que se resiste a ser desplazada y, con ellas, los modelos teóricos que nos ayudan a entenderlas. Así lo denuncia Faria, cuando pone de relieve la crisis creciente del modelo tradicional de derecho positivo, crisis que alcanza a sus mecanismos de identificación y de eficacia y que afecta de lleno a la concepción dogmática, a sus modelos explicativos y a sus esquemas teóricos desarrollados en base al primado del monismo jurídico.

Una realidad en crisis y otra que, en fase embrionaria, comienza a emerger, un nueva paradigma, cuyos perfiles y cuya estructura arquitectónica no está aún plenamente definida, 
pero que cuenta ya con rasgos distintivos y perfiles razonablemente precisos que nos permiten vislumbrar la crisis del paradigma jurídico estatalista y de los ordenamientos jurídicos cerrados, autárquicos, independientes y autosuficientes .

El signo de nuestro tiempo es la interdependencia en las relaciones sociales, políticas, jurídicas, económicas. Una interdependencia que conecta las normas creando redes flexibles que trascienden las fronteras estatales: un derecho a medias territorial, a medias desterritorializado, en el que la concepción espacial que demarcaba los límites de la validez queda frecuentemente difuminada. Esta irrupción de la interdependencia socava, evidentemente, un presupuesto básico de la teoría del ordenamiento jurídico como expresión del derecho uno y estatal: la autonomía del sistema jurídico respecto de otros órdenes normativos, una autonomía cuya crisis guarda una estrecha e íntima relación con la creciente pérdida de autonomía del Estado, la disminución competencial y el condicionamiento externo de su capacidad regulatoria. A medida que el Estado pierde capacidad de control, el derecho estatal se diluye en un medio ambiente cada vez más complejo que anuncia el declive definitivo de la autonomía del modelo jurídico estatal.

Por otra parte, la concepción tradicional del ordenamiento jurídico ha dejado ya de proporcionar un completo instrumental teórico capaz de orientar la labor de los operadores jurídicos. El jurista práctico se encuentra así ante la constatación de la pérdida de referentes, porque la vieja teoría del ordenamiento sólo puede proporcionar respuestas parciales y fragmentarias ante la compleja realidad jurídica de nuestro tiempo. El modelo teórico del ordenamiento jurídico pierde así capacidad normativa como propuesta teórica de transformación de la realidad jurídica. El derecho de nuestros días no puede ya ser reconducido a ese modelo que durante tanto tiempo inspiró la actuación de los juristas prácticos.

\section{CONCLUSION}

Las demandas de la sociedad actual requieren un nuevo modelo teórico que pueda impregnar los procesos de creación, interpretación y aplicación del derecho a partir de la consideración de las nuevas exigencias emergentes. Por citar solamente algunos: la protección de intereses difusos o la prevención de riesgos como la amenaza nuclear, la experimentación genética, las tecnologías de la información, las nuevas formas de criminalidad o el progresivo deterioro del medio ambiente no encuentran respuesta en ese marco teórico del ordenamiento 
jurídico que partía de una concepción temporal radicalmente vinculada al presente. Los nuevos procesos sociales generados en el contexto de la globalización están demandando un nuevo modelo teórico capaz de acoger en su seno las expectativas y demandas de nuestra era: un derecho capaz de afrontar desafíos globales desde una perspectiva global, un derecho capaz de superar escisiones territoriales allí donde "el fin de la geografía” resulta una realidad cada vez más incontestable en un mundo en el que las fronteras quedan frecuentemente diluidas.

Allí donde la epistemología jurídica señala un punto de ruptura, allí donde las categorías pierden su capacidad descriptiva para clasificar los objetos del derecho, allí donde los conceptos resultan insuficientes para explicar la realidad, podemos vislumbrar los síntomas de un agotamiento paradigmático: la finitud de un modelo de hacer Ciencia del derecho y de pensar sobre el fenómeno jurídico. Resulta, ciertamente, difícil aventurar más allá de la constatación escueta y lapidaria de la crisis, una crisis cuyos contornos aparecen ya cada vez más claramente perfilados por el fenómeno de la globalización: el pluralismo normativo, la desreferencialización de la ley como fuente primaria de producción jurídica, la aparición de tendencias desformalizadoras, la crisis del modelo jurídico-político estatal o la quiebra de los principios esenciales del ordenamiento jurídico constituyen signos inequívocos de ello. Por tanto, podemos concluir, en este sentido, que la globalización afecta de lleno al paradigma jurídico imperante y provoca disfunciones graves que se traducen en una crisis del modelo tradicional de pensar y hacer derecho en nuestras sociedades.

Responder a estos apremios constituye un desafío de magnitudes desconocidas para el viejo paradigma cientificista de la ciencia jurídica y provoca a la imaginación de los juristas para elaborar nuevos universos epistemológicos, desde una comprensión también nueva del derecho, de las relaciones humanas y de las coordenadas espacio-temporales en las que éstas se desenvuelven que reclaman un nuevo instrumental teórico y metodologías jurídicas también innovadoras, adecuadas a la nueva realidad del derecho global. Vivimos una época de transición paradigmática: un viejo saber jurídico se resiste a ser desplazado, mientras toman cuerpo nuevas realidades jurídicas y nuevos modelos epistemológicos, cognitivos e interpretativos, basados en el método comparatista y en una jurisprudencia generalista de vocación cosmopolita, reacia a los análisis estancos, unidimensionales, a las compartimentaciones geográficas y a la estricta configuración temporal del derecho anclada en el presente. Tiene razón Ferrarese cuando atribuye a este derecho sin demarcaciones territoriales definidas el inicio de una nueva civilización jurídica. El diritto sconfinato reclama una ciencia jurídica desprovista de la vieja matriz estatalista, plural, policéntrica y proyectada hacia nuevas dimensiones temporales, una 

REVISTA ELETRÔNICA DO CURSD DE

ciencia jurídica prospectiva comprometida con la justicia, con la dignidad de los seres humanos y con la tutela de sus derechos.

\section{REFERENCIAS}

DOMINGO OSLÉ, R. ¿Qué es el Derecho global?, Consejo General del Poder Judicial, Madrid, 2008.

FARIA, J.E. Direito e Conjuntura, Saraiva, Sao Paulo, 2008.

FARIA, J.E. Pluralismo jurídico y regulación (ocho tendencias en el derecho contemporáneo). In: DE JULIOS-CAMPUZANO, A. (ed.) Ciudadanía y Derecho en la era de la globalización, Dykinson, Madrid, 2007, pp. 115-129.

FARIA, J.E.O Direito na economia globalizada, reimpr., Malheiros, Sao Paulo, 2000.

SNYDER, F. Global Economics Networks and Global Legal Pluralism, EUI Working Papers, 99/6 European University Institute, Florencia, 1999. 